\title{
Cuffdrukmeting van levensbelang
}

\author{
Het meten van de cuffdruk in de praktijk
}

\author{
M.E.J. Munsterman
}

Veel patiënten op de IC zijn gedurende lange tijd geïntubeerd. Bij volwassenen gebruikt ieder ziekenhuis tubes met een cuff. Deze cuff kan in een zeer korte periode al zorgen voor tracheabeschadiging. Door de cuffdruk regelmatig te meten, wordt deze beschadiging aanzienlijk beperkt.

Casus Mevrouw A., een vrouw van 30 jaar, wordt opgenomen op de IC in verband met nabeademing na een grote buikoperatie. Gezien de leeftijd van mevrouw en de aard van de operatie, wordt geschat dat de geïntubeerde periode kort zal zijn. Volgens beleid van het ziekenhuis is er gekozen voor de relatief 'goedkopere' tube met een low volume high pressure cuff. Helaas volgden een aantal complicaties wat resulteerde in een langere geïntubeerde periode dan gepland, namelijk geen dag maar twee weken.

Deze hele periode heeft mevrouw A. dezelfde beademingstube met de high pressure cuff gehad. De cuffdruk is niet gecontroleerd gedurende deze twee weken. In de nacht van 2 op 3 mei overleed mevrouw A. aan de gevolgen van een trachearuptuur). Het ICpersoneel reageerde geschokt.

\section{Korte geschiedenis}

Het principe van beademen via een tube vindt zijn oorsprong in de jaren vijftig naar aanleiding van een polioepidemie in Denemarken. Door deze epidemie moesten in een korte tijd veel patiënten beademd worden, wat toen nog beademen met de ijzeren long betekende. ${ }^{1} \mathrm{Bij}$

M.E.J. Munsterman $(\square)$

IC-verpleegkundige UMCN St Radboud, Nijmegen gebrek aan voldoende apparatuur werd besloten om patiënten te intuberen en met de hand te beademen. Een machine hiervoor werd pas in 1967 bedacht. Tegenwoordig zijn er verschil lende soorten tubes te verkrijgen. Aan het einde van de tube zit een opblaasbare manchet, genaamd de cuff.

\section{Doel van de cuff}

De cuff heeft als primair doel de trachea af te sluiten bij mechanische beademing om aspiratie te voorkomen. De cuff voorkomt geen ventilator associated pneumonia (VAP) en is ook niet bedoeld voor extra fixatie. Er zijn tubes met verschillende cuffs op de markt. De cuffs zijn in te delen in twee groepen: de low volume - high pressure cuff en de high volume - low pressure cuff, waarvan de laatste steeds meer gebruikt wordt.

In tegenstelling tot de low volume - high pressure cuff, verdeelt de high volume - low pressure cuff de druk over een groter gebied trachea mucosa, hierdoor zal er minder snel schade ontstaan (zie foto's 1 en 2). Maar ook deze cuffs kunnen beschadiging aan de trachea veroorzaken wanneer ze te hard worden opgeblazen. ${ }^{11,12}$ Het insufflatiekanaal van de cuff zit verwerkt in de tube. Aan het einde zit een pilot ballon waaraan te zien is dat de cuff is opgeblazen, maar dat zegt niets over de aanwezige cuffdruk. De cuff wordt opgeblazen tot de trachea luchtdicht is afgesloten. De hoeveelheid te insuffleren lucht verschilt per persoon. ${ }^{3}$ Dit heeft te maken met de anatomie van de trachea en de maat van de tube. Een te kleine diameter van de tube in de trachea heeft meer lucht nodig om de trachea af te sluiten dan een grotere diameter. 


\section{De cuffdruk}

Hoe hoog de cuffdruk maximaal mag zijn, is berekend op geleide van de bloeddoorstroming in de trachea mucosa (zie kader 1). Wanneer de cuffdruk hoger is dan de tracheale bloeddruk, ontstaat ischemie van de mucosa. De volgende afwijkingen kunnen dan ontstaan:

1. decubitus van de trachea

2. granuloom

3. trachearuptuur

4. tracheo-oesofagale fistel

5. trachea stenose.

Een te lage cuffdruk daarentegen is ook niet wenselijk. Hoewel een cuff geen VAP voorkomt, bestaat bij een te lage cuffdruk een grotere kans op aspiratie van gecolloniseerd subglottis secreet, een gevaar voor VAP. ${ }^{5}$

$\mathrm{Er}$ is onderzoek verricht naar de invloed die verschillende houdingen van de nek hebben op de cuffdruk. Het blijkt dat de cuffdruk bij een andere houding dan de neutrale hoofdstand toch wisselt. Bij een flexie van de nek neemt de cuffdruk toe met $22 \mathrm{mmHg}$. Bij extensie en rotatie van de nek verhoogt de cuffdruk met 5 $\mathrm{mmHg} .{ }^{21} \mathrm{Bij}$ het monitoren van de cuffdruk wordt dus ook gevraagd om naar de positie van de nek te kijken. Wanneer u cuffdruk meet, moet $\mathrm{u}$ zich realiseren dat er meerdere factoren van invloed zijn op de meting. Bijvoorbeeld bij het beademen met gebruik van lachgas $\left(\mathrm{N}_{2} \mathrm{O}\right)$ moet $\mathrm{u}$ rekening houden met een kans op verhoging van de cuffdruk. Omdat lachgas de cuff in diffundeert, kan de cuffdruk ongemerkt verhogen. ${ }^{18}$

De hoogte van de cuffdruk Uit berekeningen blijkt dat bij een patiënt met een normotensie waarbij de cuffdruk onder de $25 \mathrm{mmHg}\left(30 \mathrm{~cm} \mathrm{H}_{2} \mathrm{O}\right)$ blijft, de kans op ischemische veranderingen minimaal is. $\mathrm{Bij}$ patiënten met een hypotensie en een mean arterial pressure (MAP) onder $50 \mathrm{mmHg}$, kunnen zelfs bij een cuffdruk onder de $25 \mathrm{mmHg}$ significante verminderingen in de bloeddoorstroming ontstaan. ${ }^{19}$

Kader 1 .

\section{Meten van de cuffdruk}

Uit meerdere onderzoeken over heel de wereld blijkt dat de cuffdruk niet routinematig gecontroleerd wordt. Uit onderzoek blijkt dat op de Intensive Care Units waar de handeling niet routinematig wordt uitgevoerd, de cuffs vaker te hard worden opgeblazen dan te zacht. ${ }^{5}$ In 50 procent van de gevallen blijkt dat de cuffdruk boven 30 $\mathrm{mmHg}\left(40 \mathrm{cmH}_{2} \mathrm{O}\right)$ gemeten wordt, ${ }^{7}$ terwijl een cuffdruk lager dan $25 \mathrm{mmHg}\left(30 \quad \mathrm{cmH}_{2} \mathrm{O}\right)$ sterk wordt geadviseerd. ${ }^{11,22}$ Als de druk hierboven komt, neemt de tracheale mucosa bloodflow sterk af waardoor dan ook veel meer complicaties aan de trachea worden gevonden.

De reden van het niet routinematig meten van de cuffdruk is niet helemaal duidelijk. Verpleegkundigen zijn zo alert op het voorkomen van decubitus, waarom letten zij dan niet op decubitus van de trachea? Een van de redenen kan zijn dat men niet op de hoogte is van de functie van de cuff. Er wordt nog steeds verondersteld dat de cuff gebruikt wordt om de tube beter te kunnen fixeren en zo autodetubatie te voorkomen. Bij deze beredenering is het vanzelfsprekend dat er grotere cuffdrukken worden gevonden om een betere stabilisatie van de tube te bereiken. ${ }^{8}$

Ten tweede kan het zijn dat de medici en het verplegend personeel van de Intensive Care Units het belang van de meting onderschatten. Trachealetsel door een te hoge cuffdruk ontstaat binnen aanzienlijke tijd bij 10 procent van de kritieke patiënten tijdens mechanische ventilatie. ${ }^{9}$ Zoals hierboven staat beschreven, blijkt dat het uitvoeren van een simpele handeling veel schade kan voorkomen. Er wordt dan ook geadviseerd bij een beademde patiënt de cuffdruk driemaal daags te meten. ${ }^{10}$

\section{De juiste meetmethode}

Wanneer de gevaren en de noodzaak van het meten volledig duidelijk zijn, blijft de vraag over hoe er gemeten moet worden. In de literatuur zijn diverse methoden beschreven:

Palpatie van de uitwendige pilot ballon

Als men de cuff opblaast, wordt de uitwendige pilot ballon bol. Wanneer men door middel van palpatie van het uitwendige ballonnetje een goede cuffdruk wil behalen, blijkt dat in 88 procent van de gevallen de druk op de tracheawand te hoog is. Bij deze methode werd een gemiddelde cuffdruk van $70 \mathrm{mmHg}$ ! $\left(91 \mathrm{~cm} \mathrm{H}_{2} \mathrm{O}\right)$ gevonden. ${ }^{13}$ Dit blijkt dus een niet-betrouwbare methode voor het meten van de cuffdruk.

Spuitje als uitlaatklep

Wanneer een $20 \mathrm{ml}$ spuit wordt bevestigd aan de uitwendige pilot ballon en de cuff wordt geïnsuffleerd met $15 \mathrm{ml}$ lucht, zal de lucht weer uit de cuff lopen tot deze de juiste cuffdruk heeft. De spuit blijft in situ aan de uitwendige ballon. ${ }^{14}$ Deze methode blijkt in de praktijk niet geheel functioneel omdat het spuitje niet de juiste cuffdruk behaalt en behoudt. ${ }^{15}$ Ook wordt met deze methode alleen de hoge cuffdruk gecompenseerd. Het spuitje 


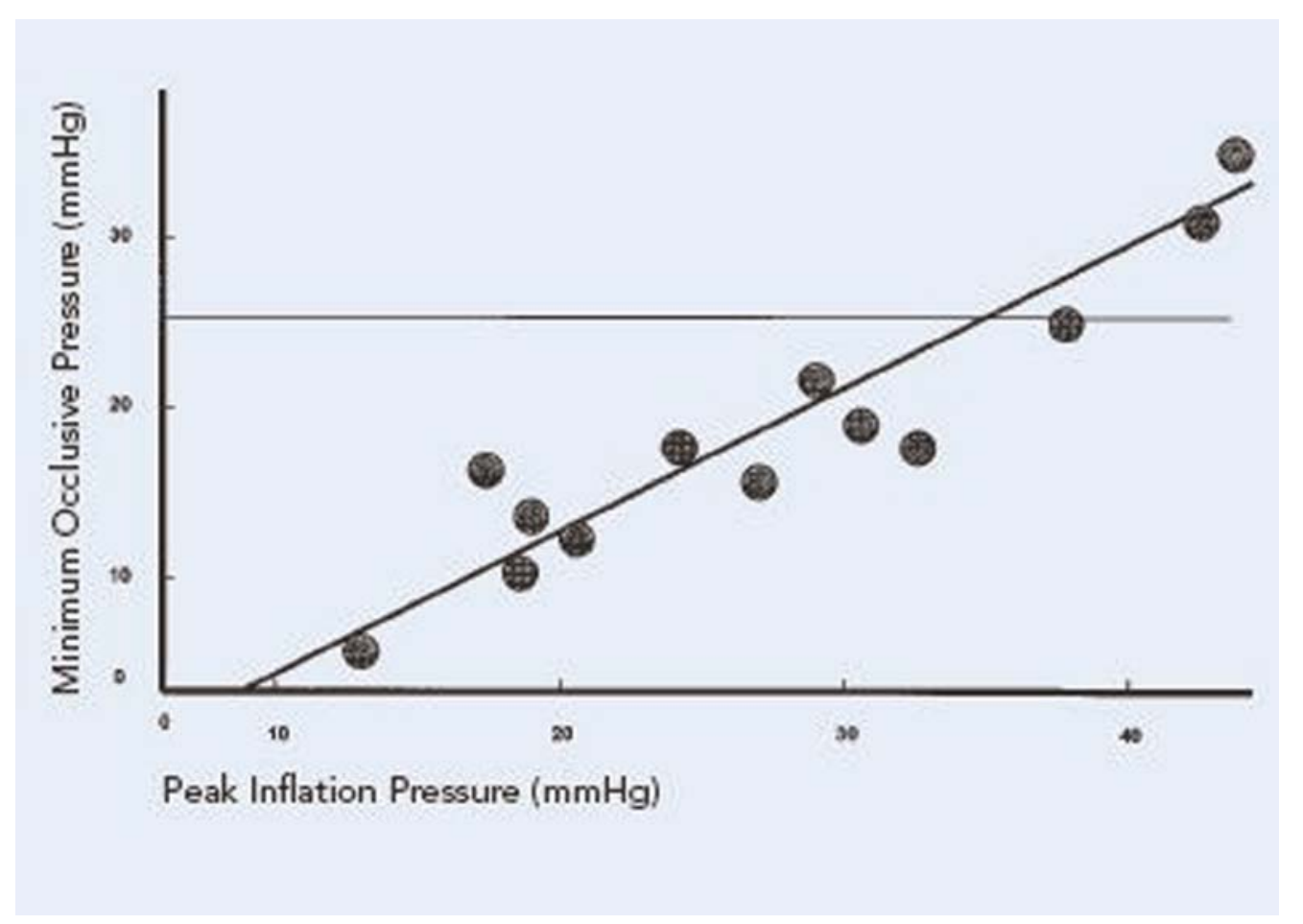

Figuur 1

blaast niet zelf op om een te lage cuffdruk te compenseren.

\section{Manometer}

Een manometer wordt aangesloten aan de pilot ballon van de cuff. De meter geeft aan wat de cuffdruk is. Meestal is er een groen gedeelte op de manometer aangegeven waar de druk in moet vallen. Bij de meeste meters valt deze tussen de $15-22 \mathrm{mmHg}(25-30 \mathrm{~cm}$ $\mathrm{H}_{2} \mathrm{O}$ ). Dit is de enige methode die daadwerkelijk een cuffdruk meet.

\section{Minimal occlusion volume (MOV)}

Deze methode wordt uitgevoerd door lucht uit de cuff te halen tot er lekkage van beademingsgassen langs de cuff ontstaat. Dit kan met een stethoscoop ter hoogte van het strottenhoofd beluisterd worden. Dan blaast men tijdens de inspiratiefase langzaam lucht in de cuff tot de lekkage is verdwenen. ${ }^{16} \mathrm{Op}$ deze manier is de trachea afgesloten met de laagst mogelijke druk. Het voordeel van deze manier is dat het opgehoopte secreet dat boven de cuff staat, door de positieve druk in de mondkeelholte wordt geblazen. Dit zou de kans op microaspiratie verkleinen. Deze methode kan alleen uitgevoerd worden bij patiënten die met positieve druk beademd worden. In de literatuur wordt vaak gerefereerd aan het onderzoek van Ganner. Daarin wordt beweerd dat de cuffdrukken te hoog blijken te zijn als de cuffdruk gemeten wordt met de MOV-techniek. ${ }^{17}$ Naar aanleiding van dit onderzoek heb ik zelf de MOV-techniek uitgevoerd. De resultaten zijn te lezen in kader 2 .

Meten met de MOV-techniek Naar aanleiding van dit onderzoek heb ik zelfstandig alle cuffs na de MOV-techniek nagemeten met een manometer. Ik heb bij vijftien verschillende patiënten de MOVtechniek toegepast volgens de methode zoals beschreven bij de MOV-techniek. Deze handeling is uitgevoerd door drie verschillende verpleegkundigen en een anesthesioloog. Door het nameten met een manometer stelde ik vast dat twaalf van de vijftien gemeten cuffdrukken binnen de geadviseerde waardes liggen, onder $25 \mathrm{mmHg}(30 \mathrm{~cm}$ $\mathrm{H}_{2} \mathrm{O}$ ). De drie patiënten bij wie een hogere cuffdruk werd gemeten, werden beademd met hoge beademingsdrukken. De cuffdruk kwam overeen met de peakdruk van de beademing.

Kader 2.

\section{Conclusie}

Uit bovenstaande blijkt dat een aantal methoden voor het meten van de cuffdruk niet betrouwbaar is, enkele andere zijn dat wel. De cuffdruk meten via de MOVtechniek heeft als voordeel dat men opgehoopt secreet 


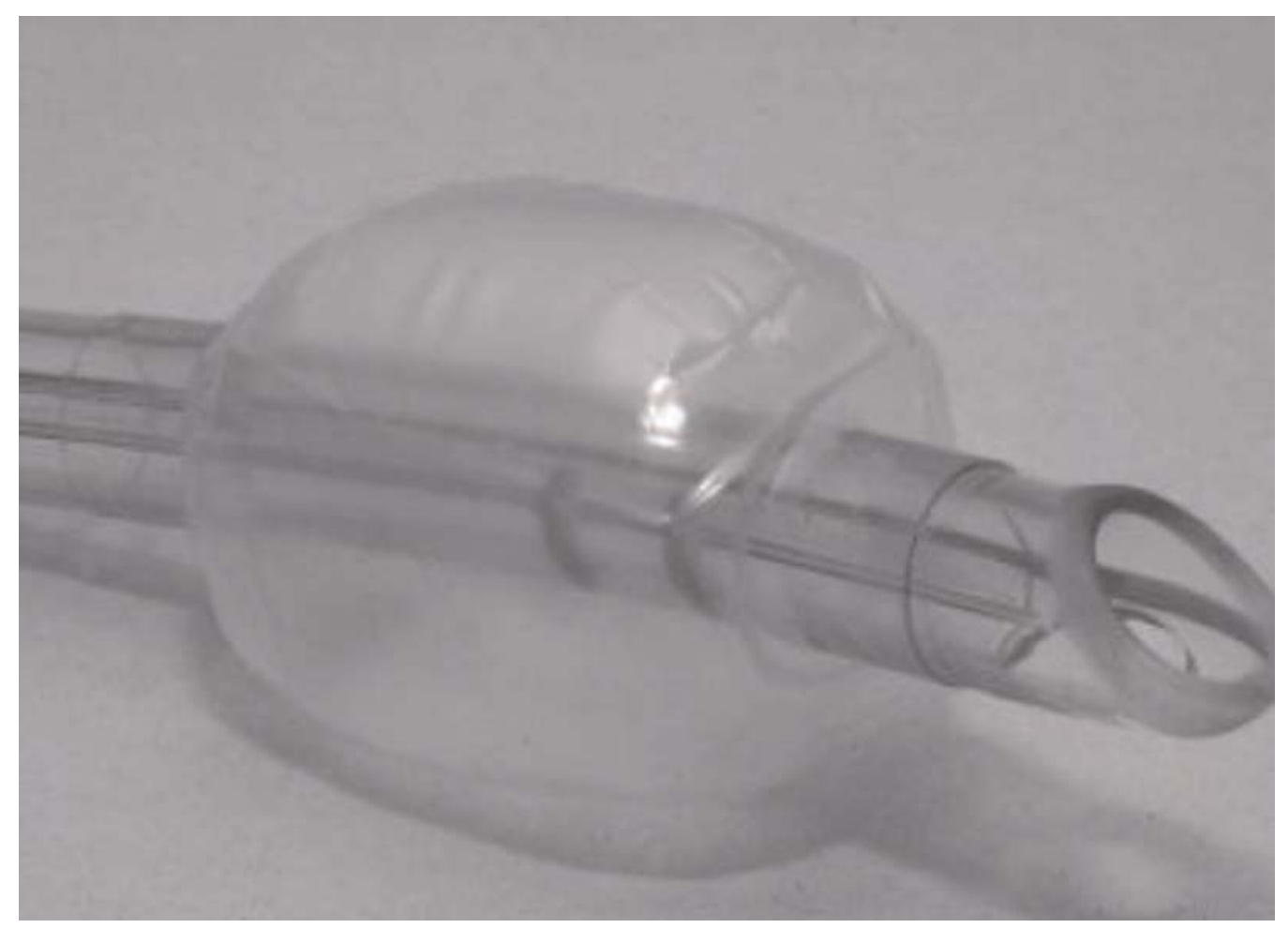

boven de cuff verwijdert en zo minder risico loopt op een VAP. Bovendien wordt via de MOV-techniek de laagst mogelijke druk toegepast en niet de 'standaard' druk van de manometer. Zoals al eerder gezegd, verschilt de hoeveelheid te insuffleren lucht per persoon. Bij patiënten die niet aan de positieve drukbeademing liggen, kan deze techniek echter niet worden toegepast en bent $u$ aangewezen op de manometer. Bij patiënten die worden beademd met hoge drukken of (respiratoir) erg instabiel zijn, is het soms lastig om de MOV-techniek uit te voeren. Dit
Foto's 1 en 2. Vormverschil tussen de high volume - low pressure cuff en de low volume - high pressure cuff.

(Fotograaf: G.P. den Bandt)

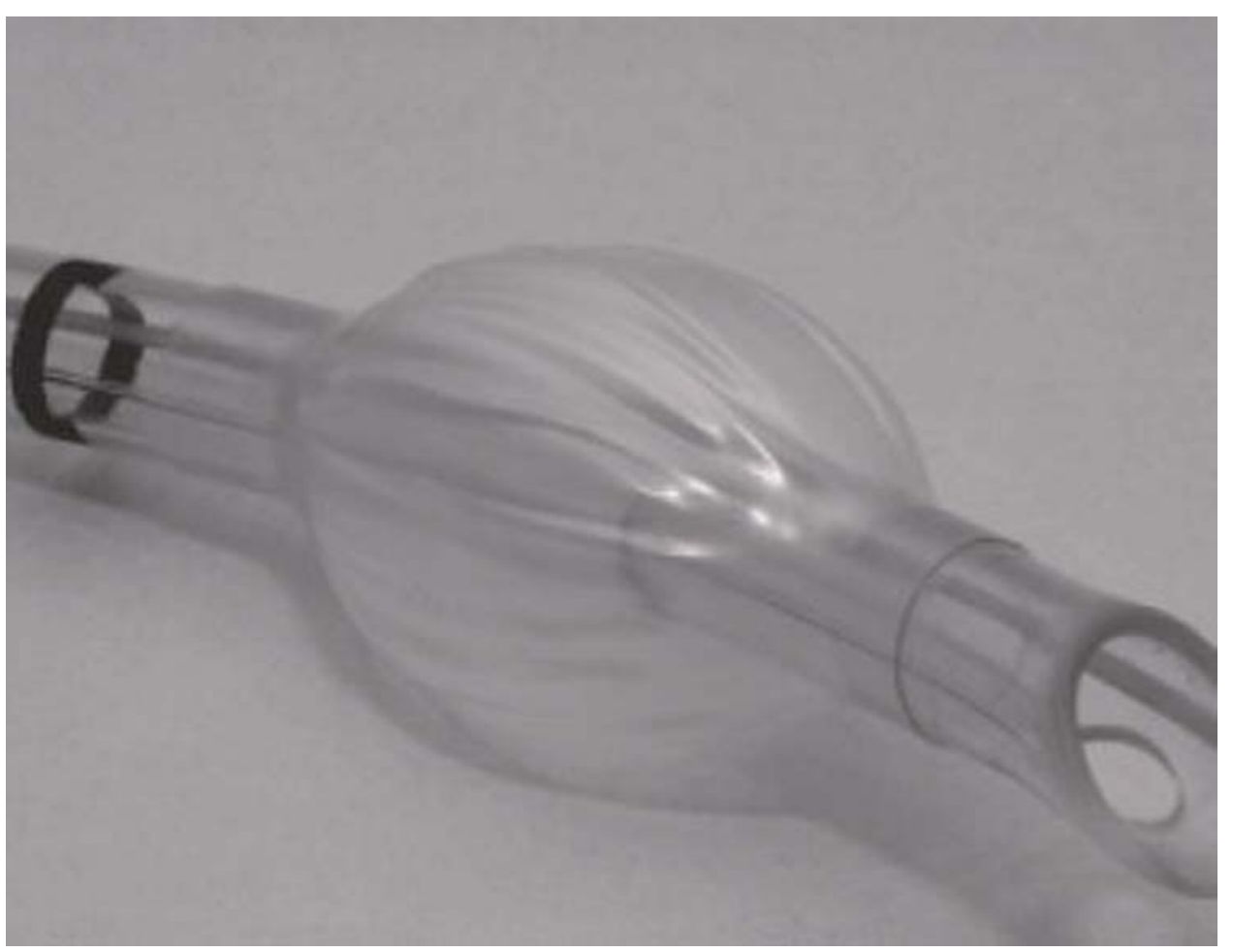


door angst voor verlies van de hoge beademingsdrukken (PEEP), desaturatie of een krachtige hoestprikkel bij instabiele neuropatiënten. In deze gevallen kunt u voor de manometer kiezen. Hierbij hoeft de cuff niet leeg te lopen met eventueel verlies aan de opgebouwde druk in de longen.

Wanneer $\mathrm{u}$ de minimal occlosion volumetechniek gebruikt, kan de minimale occlusie variëren bij de drukken van de beademing. Wanneer wordt beademd met een hogere PEEP, is er ook een hogere druk nodig om de trachea met de minimale druk af te sluiten. Er bestaat een lineare relatie tussen de minimale occlusiedruk en de peak inflatiedruk. In figuur 1 is te zien dat bij een peak inflatiedruk van meer dan $35 \mathrm{mmHg}\left(48 \mathrm{~cm} \mathrm{H}_{2} \mathrm{O}\right)$ de maximale 'veilige' grens van de cuffdruk wordt overschreden. ${ }^{20}$

Uit bovenstaande blijkt dat door het systematisch meten en corrigeren van de cuffdruk veel schade kan worden voorkome cuffdruk in het dagelijkse schema van de basiszorg te implementeren. Er wordt geadviseerd om de meting eenmaal per dienst te verrichten. De voorkeur voor de meetmethode gaat uit naar de MOVtechniek. Bij instabiele patiënten kan er worden gekozen om de manometer te gebruiken.

Met dank aan T. Haans, nurse-practitioner, UMC Nijmegen.

\section{Literatuur}

http://www.wetenschapsagenda.leidenuniv.nl/content_docs/oraties 2003/oratie p.c.m. van den berg.pdf

http://nl.wikipedia.org/wiki/_Jzeren_Long

Brink, van den GTWJ, Lindsen F, Uffink Th JA. Leerboek intensive care-verpleegkundige deel 2. 2004 Elsevier/gezondheidszorg. Maarssen, ISBN 9035225872

Galinski M, Tréoux V, Garrigue B, Lapostolle F, Borron SW, Adnet F. Intracuff pressures of endotracheal tubes in the management of airway emergencies: the need for pressure monitoring. Annals of emergency medicine. Volume 47, issue 6, June 2006 pages 545-547.

Wujtewicz MA, Sawicka W, Sein Anand J, Owczuk R, Wujtewicz M, Puchalski W, Bukowska A, Chodorowski Z. Monitoring of tracheal tube cuff pressure in patients treated in intensive therapy unit and intensive care units. Przegla ¿d lekarski 2004;61(4):353-5

Vyas D, Inweregbu K and Pittard A. Measurement of tracheal tube cuff pressure in critical care. Anaesthesia 2002 March; vol 57 issue $3 ; 275$
Braz J.R, Navarro L.H, Takata I. H, ascimento Junior P. Endotracheal tube cuff pressure: need for precise measurement. Sao Paulo Medical Journal 1999 Nov 4; 117(6):243-7

Mol DA, De Villiers Gdu T, Claassen AJ, Joubert G. Use and care of an endotracheal/tracheostomy tube cuff - are intensive care unit staff adequately informed. South Africa Journal of Surgery $2004 \mathrm{Feb} ; 42(1): 14-6$

Guyton D, Banner MJ and Kirby RR. High-volume low-pressure cuffs. Are they always low pressure? Chest 1991 vol 100 10761081

Granja C, Faraldo S, Laguna P, Gois L. Control of the endotracheal tube cuff balloon pressure as a method of preventing laryngotracheal lesions in critically ill intubated patients. Rev Esp Anesthesiol Reanim. 2002 Mar;49(3):137-40.

Seegobin RD, Hasselt van GL. Endotracheal cuff pressure and tracheal mucosal blood flow: endoscopic study of effects of four large volume cuffs. British Medical Journal. 1984 Mar 31;288 (6422):965-8

H.Kaloud, F.M. Smolle-Juettner, G Prause and WF List. Iatrogenic ruptures of the tracheobronchial tree. Chest 1997; vol 112:774-778

Hoffman RJ, Parwani V, Hahn IH. Experienced emergency medicine physicians cannot safely inflate or estimate endotracheal tube cuff pressure using standard techniques. merican journal of Emergency Medicine 2006 Mar;24(2):139-43

Somri M, Fradis M, Malatskey S, Vaida S, Gaitini L. Simple online endotracheal cuff pressure relief valve. The Annals of Otology, rhinology and laryngology.2002 Feb;111(2):190-2

http://homepages.cae.wisc.edu/^ bme402/cuff_valve_s06/reports/ Report_Final.pdf

http://www.nvicv.nl/LPRIC/SH/Beademing/Cuffdrukmeting.htm

Ganner C. The accurate measurement of endotracheal tube cuff pressures. British Journal of Nursing. 2001 sept 27-oct 10;10 (17):1127-34.

Tu HN, Saidi N, Leiutaud T, Bensaid S, Menival V, Duvaldestin P. Nitrous oxide increases endotracheal cuff pressure and the incidence of tracheal lesions in anesthetized patients. Anesthesia-Analgesia. 1999 Jul;89(1):187-90

Bunegin L, Albin MS, Smith RB. Canine tracheal blood flow after endotracheal tube cuff inflation during normotension and hypotension. Anesthesia-Analgesia. 1993 May;76(5):1083-90.

Guyton DC, Barlow MR, Besselievre TR. Influence of airway pressure on minimum occlusive endotracheal tube cuff pressure. Critical Care Medicine. Volume 25 (1) January 1997 91-94

Brimacombe J, Keller C, Giampalmo M, Sparr HJ, Berry A. Direct measurement of mucosal pressures exerted by cuff and noncuff portions of tracheal tubes with different cuff volumes and head and neck positions. Brithish Journal of Anaesthesia 1999;82(5):708-11

Sengupta P, Sessler DI, Maglinger P, Wells S, Vogt A, Durrani J, Wadhwa A. Endotracheal tube cuff pressure in three hospitals, and the volume required to 